\title{
Fusion of HIV-I Tat protein transduction domain to poly-lysine as a new DNA delivery tool
}

\author{
H Hashida', ${ }^{1,3}$ M Miyamoto*, I,3, Y Cho', Y Hida', K Kato', T Kurokawa', S Okushiba', S Kondo', \\ $H_{\text {Dosaka-Akita }}{ }^{2}$ and $H$ Katoh $^{1}$
}

'Department of Surgical Oncology, Division of Cancer Medicine, Hokkaido University Graduate School of Medicine, N-I 5, W-7, Kita-ku, Sapporo, Hokkaido 060-8638, Japan; ${ }^{2}$ Department of Medical Oncology, Division of Cancer Medicine, Hokkaido University Graduate School of Medicine, Hokkaido, Japan

\begin{abstract}
Effective gene therapy depends on the efficient transfer of therapeutic genes to target cells. None of the current technologies, however, satisfy all of the requirements necessary for gene therapy, because the plasma and nuclear membranes of mammalian cells are tight barriers against gene transfer using synthetic delivery systems. The protein transduction domain (PTD) of human immunodeficiency virus type I (HIV-I) Tat protein greatly facilitates protein transfer via membrane destabilisation. We synthesised polylysine peptides containing Tat PTD (TAT-pK), or other sequences, and investigated their potential as agents for gene transfer. The synthesised polypeptide TAT-pK retains DNA binding function and mediates delivery of a reporter gene to cultured cells. RGD motif binds with low affinity to alpha integrins which induce cell activation. Two control polypeptides, GGG-pK and RGD-pK, were synthesised and tested, but their gene transfer abilities were weaker than those of TAT-pK. TAT-pK-mediated gene transfer was enhanced in the presence of chloroquine or ammonium chloride, to a greater extent than that of cationic lipid-mediated gene transfer in most cancer cell lines tested. These data suggest that TAT-pK may be a potent candidate delivery vehicle that promotes gene transfer, dependent on the endocytic pathway. We conclude that the TAT-pK/DNA complex is useful as a minimal unit to package therapeutic genes and to transduce them into mammalian cells.
\end{abstract}

British Journal of Cancer (2004) 90, 1252- 1258. doi:I0.1038/sj.bjc.660 I680 www.bjcancer.com

Published online 24 February 2004

(c) 2004 Cancer Research UK

Keywords: HIV Tat protein; poly-lysine; DNA delivery

Gene therapy for cancer has been developed and a number of clinical therapeutic protocols are now being investigated. Vectors based on various viruses are useful for delivering therapeutic genes into primary cells in vitro and have also been applied in a number of gene therapy trials with humans. Viruses have some disadvantages as tools for medical application, however, with many elements of their biology yet to be elucidated. The utility of viral vectors for gene therapy is limited by DNA carrying capacity, difficulty in reliable and cost-effective manufacturing, and by immunogenicity and other safety concerns. One goal of cancer gene therapy is the development of gene delivery tools with lowered immunogenicity. While the construction of some viral vectors with reduced immunogenicity have been reported (Fisher et al, 1996; Haecker et al, 1996; Kochanek et al, 1996; Kumar-Singh and Chamberlain, 1996; Morral et al, 1999), preparation of these vectors is difficult because the virus is composed of several kinds of large molecules.

Two elements are necessary to efficiently express foreign genes in cells: passage of DNA across the cell membrane and transport into the nucleus (Colin et al, 2000). From this point of view,

\footnotetext{
* Correspondence: Dr M Miyamoto;

E-mail:m-miyamo@med.hokudai.ac.jp

${ }^{3}$ These authors have contributed equally to this work.

Received 18 January 2003; revised 2 January 2004; accepted 7 January 2004; published online 24 February 2004
}

recombinant viral vectors have a great advantage by depending on their intrinsic machinery for infection. Basic peptides derived from human immunodeficiency virus type 1 (HIV-1) Tat protein and Drosophila Antennapedia protein have been reported to translocate through the cell membrane and to carry exogenous molecules into the cytoplasm and nucleus (Derossi et al, 1994, 1996; Vivès et al, 1997; Nagahara et al, 1998; Schwartz et al, 1999; Dostman et al, 2000). HIV-1 Tat is an 86 amino-acid protein, and aa 47-57 of Tat (YGRKKRRQRRR) possess a high net positive charge at physiological $\mathrm{pH}$, with nine of its 11 amino acids being either arginine or lysine. Fusion of several proteins and this 11 aa region of Tat protein enables the delivery of proteins into cells. Thus, this 11 aa region is considered a protein transduction domain (PTD). A $119-\mathrm{kDa}$ protein, $\beta$-galactosidase, genetically fused to HIV-1 Tat PTD, was successfully carried into various mouse tissues, including the brain, following intraperitoneal injection (Nagahara et al, 1998).

Molecular conjugates of poly-lysine with natural or artificial ligands utilise the DNA-binding and -condensing properties of poly-lysine to mediate interaction with DNA (Wagner et al, 1991; Perales et al, 1994). Upon formation of a DNA-poly-lysine-ligand complex (polyplex (Felgner et al, 1997)), gene transfer is facilitated via receptor-mediated endocytosis.

In this study, we investigated the potential of a poly-lysine fused Tat PTD (TAT-pK) as a gene delivery agent. We demonstrate that TAT-pK combines with DNAs and efficiently transports them into several human cell lines. 


\section{MATERIALS AND METHODS}

\section{Reagents}

Reagents were obtained from the following sources: chloroquine and ammonium chloride from WAKO Pure Chemical Industries, Ltd. (Osaka, Japan); 2,3-dioleyloxy- $N$-[2-(sperminecarboxamido)ethyl]- $N^{\prime \prime} N$-dimethyl-1-propanaminium trifluoroacetate (DOSPA)/dioleoyl phosphatidylethanolamine (DOPE) (LipofectA$\mathrm{MINE}^{\mathrm{TM}}$ ) from Life Technologies, a division of Invitrogen (Rockville, MD, USA).

\section{Cell lines}

The human embryonic kidney cell line HEK 293 was obtained from CLONTECH Laboratories. Human pancreatic carcinoma cell lines PCI10, PCI19, PCI35, and PCI43 were generously provided by Dr Yoshiki (Hokkaido University, Japan). Human oesophageal squamous cell carcinoma cell lines TE2, TE5, TE8, and TE13 were provided by Dr Nishihira (University of Tohoku, Japan). These cell lines were cultured in Dulbecco's modified Eagle's medium (DMEM; GIBCO, Rockville, MD, USA) with $2 \mathrm{~mm}$ L-glutamine, supplemented with $10 \%$ heat-inactivated foetal calf serum (FCS), at 5\% CO2. Human lung carcinoma cell lines A549, RERF-LC-MS, and PC3 were obtained from the Japanese Cancer Research Resources Bank (Tokyo, Japan) and NCI-H226 was obtained from American Type Culture Collection (Manassas, VA, USA). They were maintained in RPMI medium (GIBCO) with 10\% FCS.

\section{Polypeptides synthesis}

Three pKs (TAT-pK, RGD-pK, GGG-pK) and TAT were supplied by Hokkaido System Science Co.,. Ltd. (Sapporo, Japan). They were chemically synthesised by solid-phase methods, using Fmoc (9-fluorenylmethyloxycarbonyl) with a Pioneer ${ }^{\text {TM }}$ Peptide Synthesis System (Applied Biosystems, CA, USA). Primary structures of the polypeptides were shown in Table 1.

\section{Plasmid DNAs}

The expression plasmid for enhanced green fluorescent protein (EGFP) (CLONTECH Laboratories, CA, USA) was constructed by inserting the cDNA into pcDNA3.1 + to produce pcDNA-EGFP. The expression vector for firefly luciferase pGL3 was obtained from Promega Corp (Madison, WI, USA).

\section{Agarose gel electrophoresis of DNA-peptides complex}

For the agarose gel electrophoresis assay, $0.5 \mu \mathrm{g}$ of DNA (lambda DNA/HindIII digest) and peptides were mixed and incubated for $10 \mathrm{~min}$ at room temperature. The samples were loaded on a $1 \%$ agarose gel containing $0.5 \mu \mathrm{g} \mathrm{ml}^{-1}$ of ethidium bromide and run for $30 \mathrm{~min}$ at $100 \mathrm{~V}$ in $1 \times \mathrm{TBE}$ buffer.

\section{Transfection conditions}

A standard protocol for gene transfer into cultured cells was followed. Cells were seeded at $2 \times 10^{4}-1 \times 10^{5}$ cells well $^{-1}$ in tissue culture plates, and cultured for $6 \mathrm{~h}$. The cells were washed once

Table I Primary structures of synthesised polypeptides

\begin{tabular}{ll}
\hline Peptides & Sequences \\
\hline TAT-pK & $\mathrm{NH}_{2}-$ YGRKKRRQRRR-GGG-KKKKKKKKKKKKKKKKK -COOH \\
RGD-pK & $\mathrm{NH}_{2}-$ AIRGDTFATGAS-GGG-KKKKKKKKKKKKKKKK -COOH \\
GGG-pK & $\mathrm{NH}_{2}-$ GGG-KKKKKKKKKKKKKKK $-\mathrm{COOH}$ \\
TAT & $\mathrm{NH}_{2}-$ YGRKKRRQRRR-GGG $-\mathrm{COOH}$ \\
\hline
\end{tabular}

with serum-free medium and incubated with medium containing DNA, DNA-peptides complex, or DNA complexed with cationic lipids (DOSPA/DOPE) for $8 \mathrm{~h}$ at $37^{\circ} \mathrm{C}$. The cells were cultured for $48 \mathrm{~h}$ in medium with $10 \%$ FCS before assaying for the expression of reporter genes. DNAs were complexed with cationic lipids, according to the procedures recommended by the suppliers.

\section{Luciferase assay and UV microscopy}

Luciferase activity was evaluated using the Luciferase Assay System (Promega) and relative light units (RLU) were measured with Mini Lumat LB 9506 (BERTHOLD, Germany). RLUs are shown as averages with standard deviations. GFP and FITC were detected with fluorescence microscopy (Olympus Optical Co. Ltd., Japan) using a GFPA cube. The cell nucleus was localised with fluorescence microscopy, using the fluorescent DNA binding dye, Hoechst 33342, and a WU cube (Olympus Optical Co. Ltd.). FITC labelled DNA fragments were prepared by phosphoramidite synthesis and purified by RP-HPLC purification.

\section{WST-8 assay}

Cytotoxicity of peptides was investigated using WST-8 assay. HEK293 cells were seeded in 96-well tissue culture plate at a density of $2 \times 10^{4}$ cells per well and incubated at $37^{\circ} \mathrm{C}$ for $72 \mathrm{~h}$ in fresh medium containing various peptides at a concentration of $10-320 \mu \mathrm{g} \mathrm{ml}^{-1}$. After incubation, $10 \mu \mathrm{l}$ of 2-(2-methoxy-4-nitrophenyl)-3-(4-nitrophenyl)-5-(2,4-disulphophenyl)-2H-tetrazolium (WST-8; Wako Pure Chemical Industries, Ltd, Japan) were added to each well. After $4 \mathrm{~h}$ of incubation, the optical density was read on a microplate autoreader (SPECTRAmax ${ }^{\mathbb{R}}$ 190; Molecular Devices Corp, Sunnyvale, CA, USA) using a test wavelength of $490 \mathrm{~nm}$ and a reference wavelength of $620 \mathrm{~nm}$.

\section{FACS analysis}

Where indicated, 10000 events were counted on a Becton Dickinson FACScan analyzer (Becton Dickinson, Franklin Lakes, NJ, USA) using a $15 \mathrm{~mW}$ air-cooled argon laser set at $488 \mathrm{~nm}$, and recorded with a $530 \mathrm{~nm}$ emission filter in the FL1 emission channel. Cell populations are represented on a FACS histogram plotting FITC intensity on a logarithmic scale against cell number. Fluorescence intensity of cell populations is indicated by a shift to the right of the histogram plots of treated cells. Fluorescence enhancement was determined by obtaining the number of gated fluorescent events for untreated and treated cells.

\section{RESULTS}

\section{DNA mobility shift analyses of pKs using agarose gel electrophorase}

The pK tracts should impart DNA binding function to the fusion protein, by interacting with the negatively charged phosphate backbone of nucleic acids. To determine DNA binding ability, increasing concentrations of peptides were incubated with constant amounts of DNA marker ( $\lambda /$ HindIII), and the resulting effects on DNA mobility were analysed on agarose gels (Figure 1). At concentrations where peptides completely bind and thus neutralise the DNA, it appears immobilised on the gel. The DNA was immobilised with peptides at a protein-toDNA $\left(\mathrm{w} \mathrm{w}^{-1}\right)$ ratio of 1 . These results show that peptides can bind DNA. Furthermore, excess amounts of peptides did not induce the DNA to migrate in the opposite direction from the positive electrode. 


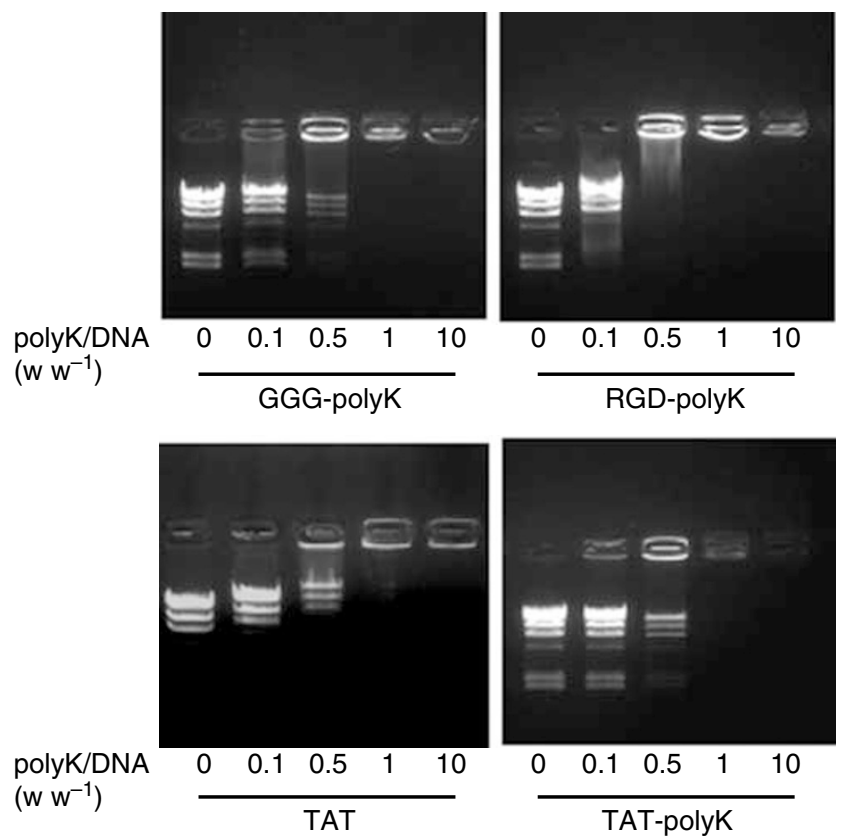

Figure I DNA mobility shift analyses of pKs. Synthesised pKs bind to plasmid DNA electrically. Three pKs were preincubated with $0.5 \mu \mathrm{g}$ of $\lambda /$ HindllI DNA marker. The plasmid DNA was electrophoresed alone or after preincubation with a given concentration $(0.05-5 \mu \mathrm{g})$ of polypeptides All plasmids were immobilised with pKs at a protein-to-DNA $\left(w^{-1}\right)$ ratio of $\mathrm{I}$.

\section{Induction of EGFP and luciferase gene expressions by various peptides}

We examined the efficiency of peptide-mediated gene transfer by evaluating the expression of the complexed EGFP gene. Under standard transfection conditions, we detected strong EGFP expression in approximately 5\% of HEK 293 cells treated with the TAT-pK/pcDNA-EGFP complex. In cells treated with the GGG-pK/ or RGD-pK/pcDNA-EGFP complex, however, EGFP expression was detected in less than $1 \%$ of cells (Figure $2 \mathrm{~A}$ ). The number of cells expressing EGFP increased in proportion to the dose of $\mathrm{pKs} / \mathrm{DNA}$ complex (figure not shown). In this study, the RGD-pK/DNA complex was also introduced into cells in a dose-dependent manner, but there was no difference in the transduction efficiency of RGD-pK and of GGG-pK. On the other hand, DNA complexed with TAT-pK was efficiently introduced, even at lower doses. The transduction efficiency of TAT peptide without a sequence of poly-lysine was lower than those of $\mathrm{pKs}$ (Figure 2B).

\section{Cell-binding activities evaluated by FACScan}

To investigate the reason for the high efficiency of TAT-pKmediated gene transfer, cell-binding activity of $\mathrm{pK} / \mathrm{DNA}$ complexes using FITC-labelled DNA was assessed (Figure 3A-H). There was scarcely any complex bound to cells with GGG-pK (Figure 3A) and RGD-pK (Figure 3B), and the amount of complex bound to cells did not increase, even $6 \mathrm{~h}$ after incubation (data not shown). TATpK/DNA complex, however, bound to almost all cells 60 min after incubation (Figure 3C). The difference in binding activity between TAT-pK and other pKs should be reflected in the DNA transduction efficiency. Interestingly, treatment with a small quantity of TAT-pK/DNA complex rarely led to cell binding (Figure 3D), and less than $0.1 \%$ of cells expressed EGFP when exposed to the equivalent quantity of TAT-pK/pcDNA-EGFP (data not shown). Most of the TAT-pK/DNA complex binds to the cells
A

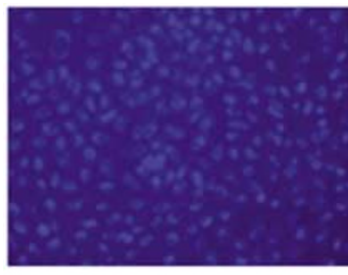

DNA alone

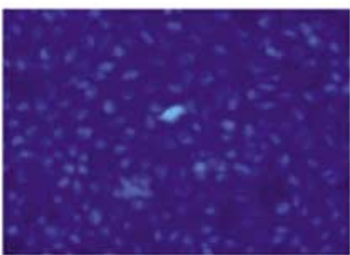

RGD-pK/DNA

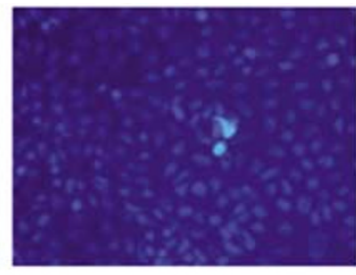

GGG-pK/DNA

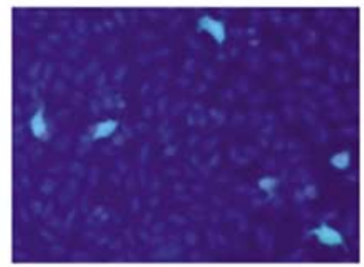

TAT-pK/DNA
B

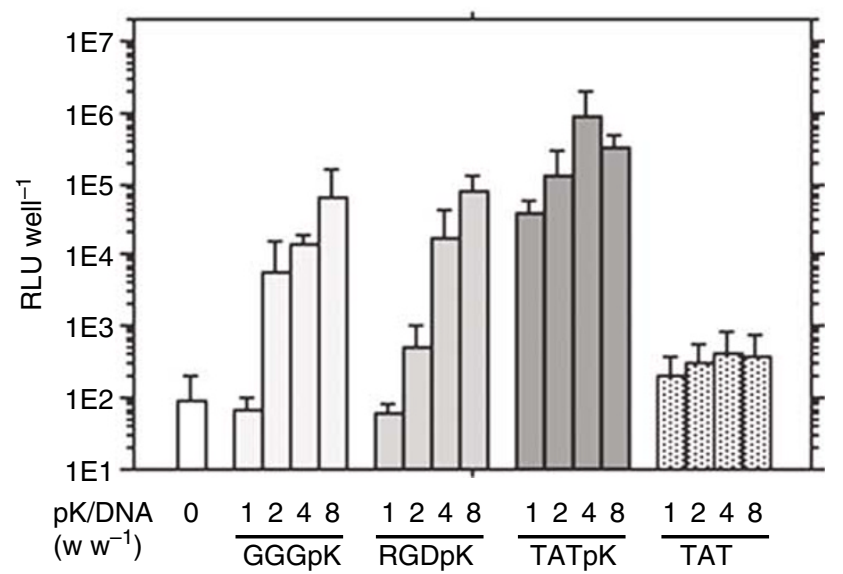

Figure 2 Induction of marker gene expression by various pKs. (A) In situ detection of pK-mediated GFP gene expression in HEK 293 cells. Cells were seeded in 12-well tissue culture plates at a density of $5 \times 10^{4}$ cells well $^{-1}$. The cells were treated with $\mathrm{pK} / \mathrm{pcDNA}$-EGFP complex ( $12 \mu \mathrm{g}$ of pKs and $3 \mu \mathrm{g}$ of DNA) as described under Materials and Methods. After $8 \mathrm{~h}$, medium with I0\% FCS was added, and the cells were grown for another $48 \mathrm{~h}$ before fluorescent microscopic observation. (B) Induction of peptide-mediated luciferase gene expression. Cells were seeded in six-well tissue culture plates at a density of $1 \times 10^{5}$ cells well $^{-1}$. The cells were treated with peptide/pGL3-promoter complex ( $5 \mu \mathrm{g}$ of DNA). After $8 \mathrm{~h}$, medium with $10 \%$ FCS was added, and the cells were grown for another $48 \mathrm{~h}$ before they were harvested for analysis. Luciferase activity was evaluated using the Luciferase Assay System (Promega) and estimated in average relative light units (RLU) with standard deviations.

10-30 min after incubation (Figure $3 \mathrm{E}$ and F). Tat-(48-60) has been reported to enter cells extremely rapidly, reaching the nucleus within $5 \mathrm{~min}$ (Futaki et al, 2001). Similarly, in our analysis, binding activity was observed immediately after incubation, and $1 \mathrm{~h}$ after incubation, FITC emission was detected in the nucleus (Figure 3I). No FITC emission was observed in cells exposed to the other pK/DNA complexes (data not shown). On the other hand, a four-fold excess of peptides, for neutralisation of the electrical charge, was required for high affinity (Figure $3 \mathrm{G}$ and $\mathrm{H}$ ). A large number of peptides appear to require the complex to remain stably on the cell membrane or in the cytoplasm. 

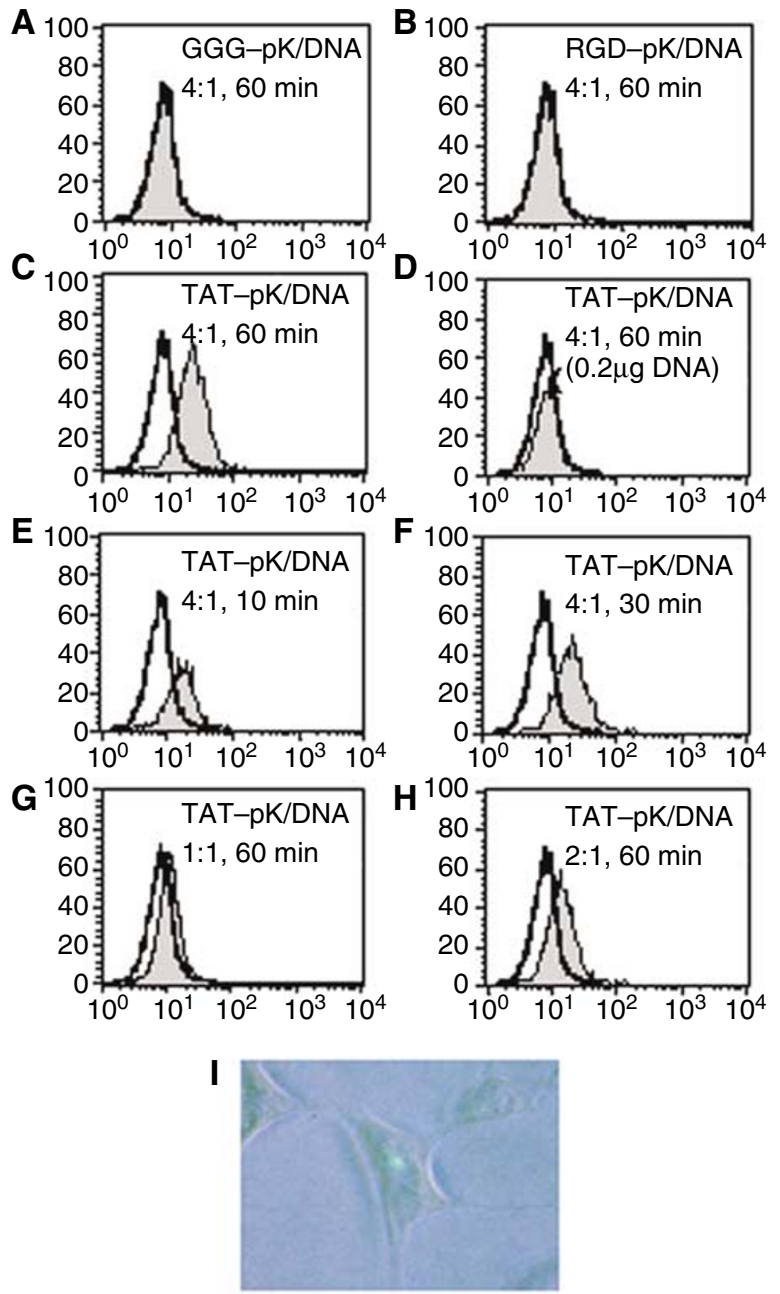

Figure 3 Cell binding activity of pK/DNA complex. HEK 293 cells were grown on 12-well dishes. Peptides and FITC-labelled-DNA were incubated together at the indicated ratios, at room temperature for $5 \mathrm{~min}$ in $\mathrm{I} \mathrm{ml}$ of serum-free DMEM, and then added to cell monolayers. Cells were exposed to mixtures ( $2 \mu \mathrm{g}$ of DNA) for $60 \mathrm{~min}$ at $37^{\circ} \mathrm{C}, 5 \% \mathrm{CO}_{2}$ (A-C). Cells exposed to mixtures containing $0.8 \mu \mathrm{g}$ of TAT-pK and $0.2 \mu \mathrm{g}$ of DNA for $60 \mathrm{~min}(\mathbf{D}), 8 \mu \mathrm{g}$ of TAT-pK and $2 \mu \mathrm{g}$ of DNA for $10 \mathrm{~min}(\mathbf{E})$ and $30 \mathrm{~min}$ $(\mathbf{F})$, indicated ratios of TAT-pK and $2 \mu \mathrm{g}$ of DNA for $60 \mathrm{~min}(\mathbf{G}, \mathbf{H})$. In situ detection of TAT-pK/FITC-labelled-DNA complexes (I). Cells were exposed to mixtures containing $8 \mu \mathrm{g}$ of TAT-pK and $2 \mu \mathrm{g}$ of DNA for $2 \mathrm{~h}$ and FITC was detected with fluorescent microscopy as described under Materials and Methods.

\section{Cytotoxicity of pKs evaluated by WST-8 assay}

The cytotoxicity of the three pKs was investigated after incubating 293 cells with peptide concentrations up to $320 \mu \mathrm{g} \mathrm{ml}^{-1}$ for $72 \mathrm{~h}$. The cytotoxicity of TAT-pK and of RGD-pK were almost equal, while that of GGG-pK was slight (Figure 4).

\section{Characterisation of TAT-pK-mediated gene transfer in HEK 293 cells}

TAT-pK-mediated EGFP expression was dramatically improved in the presence of $100 \mu \mathrm{m}$ chloroquine (Figure 5A). Efficiency of TATpK-mediated luciferase expression was also elevated dose-dependently, but exposure to excess amounts of agent reduced the luciferase activity (Figure 5B). Moreover, as TAT-pK contains a GRKKR nuclear localisation signal within its sequence, we thought it would be advantageous for cellular gene expression. These

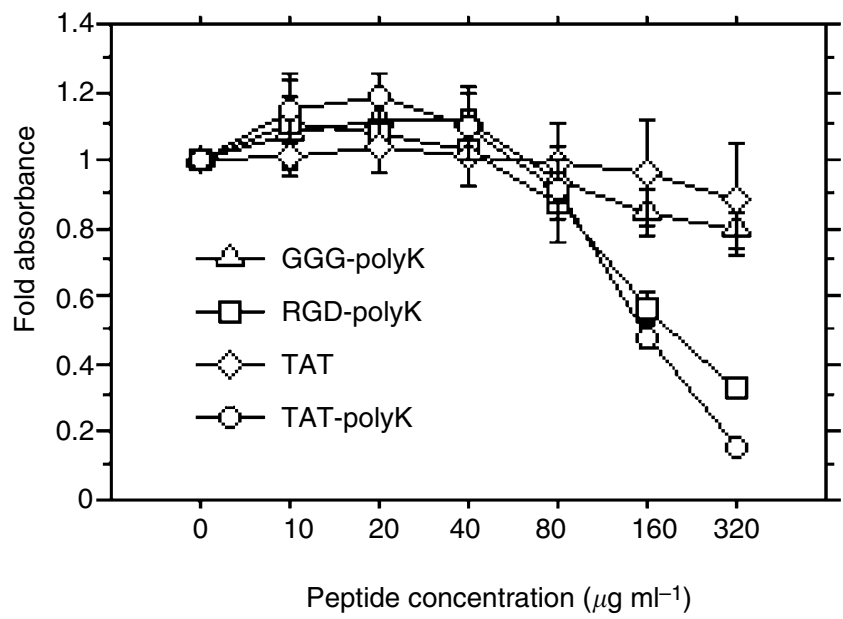

Figure 4 Cytotoxicity of polypeptides on HEK 293 cells. Cells were seeded into 96 -well plates and incubated at $37^{\circ} \mathrm{C}$ for $72 \mathrm{~h}$ in fresh medium containing a given concentration of various polypeptides. Absorbance was measured by the WST-8 assay, as described under Materials and Methods. Each end point represents the mean \pm s.d.

functions are similar to those of viral vectors that actively bind to the cell surface via high-affinity ligands, and transport their DNA into the nucleus by endocytosis. Thus, TAT-pK/DNA complexes possess the necessary elements for transfection as a small particle, although the efficiency is lower than that of adenoviral vectors. When we compared the efficiency of TAT-pK-mediated gene transfer with that mediated by cationic lipids (DOSPA/DOPA), we found that TAT-pK can induce higher levels of luciferase activity in the presence of chloroquine, but not in its absence (Figure 5B). The cytotoxicity of ammonium chloride or chloroquine was investigated (Figure 5C). Both of ammonium chloride and chloroquine showed cytotoxicity at a higher concentration. There were no cytotoxic effects with TAT-pK.

\section{TAT-pK-mediated transduction efficiency in various human cancer cell lines}

To utilise TAT-pK for various purposes, we investigated the efficiency of TAT-pK-mediated luciferase gene transfer using several human cancer cell lines that tend to accept gene transfer with low efficiency (Figure 6). The TAT-pK complex was successfully introduced into almost all cell lines at superior levels to DOSPA/DOPA, in the presence of chloroquine.

\section{DISCUSSION}

In order to be utilised for gene therapy, gene delivery systems require convenience and safety. Even transporting a single DNA encoding a small protein needs a vector construct. Moreover, the vector has longer DNA and 'the shell' that wraps it. Because large vectors may have adverse effects, our aim was to construct the smallest possible unit permitting efficient and safe transfection of DNA into mammalian cells. Cationic polypeptides, such as polyarginine and poly-lysine, have been reported to bind DNA, form complexes with DNA, and introduce themselves into cells (Wagner et al, 1991; Perales et al, 1994; Felgner et al, 1997; Futaki et al, 2001; Suzuki et al, 2002). Their efficiency for practical applications to gene therapy, however, remains untested. In the present study, we fused the Tat PTD to poly-lysine in order to improve the efficiency of DNA delivery.

As the pancreatic cancer cell line PCI35 has poor DNA transfection efficiency with cationic liposomes, we investigated 
A
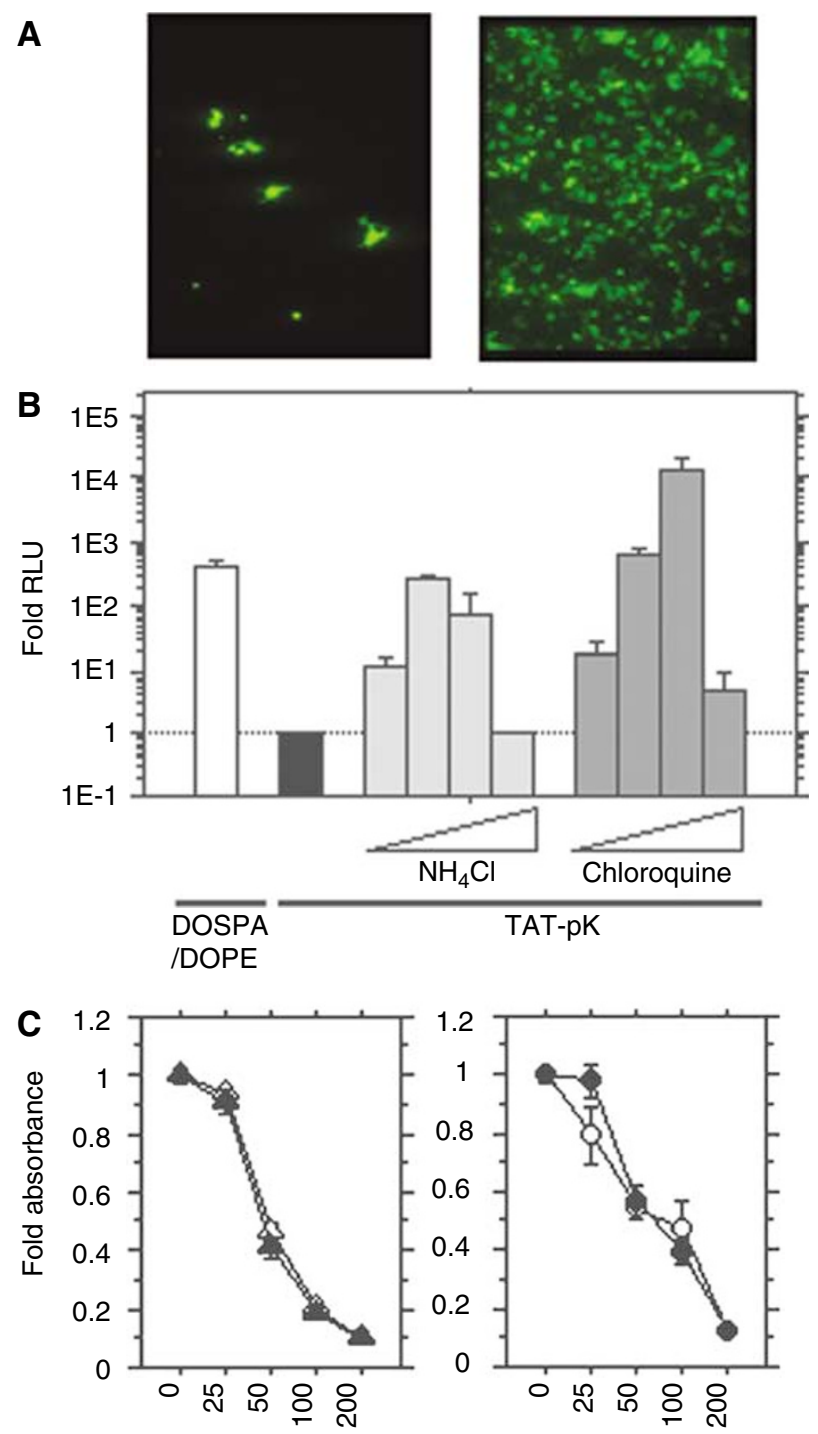

$\mathrm{NH}_{4} \mathrm{Cl}(\mathrm{mm})$

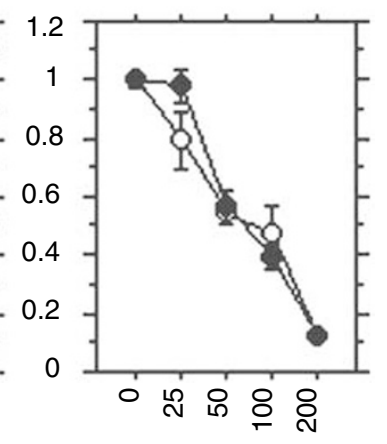

Chloroquine $(\mu \mathrm{m})$

Figure 5 Characterisation of TAT-pK-mediated gene transfer in HEK 293 cells. (A) Enhancement of TAT-pK-mediated GFP gene expression in HEK 293 cells. Cells were seeded in 24-well tissue culture plates at a density of $2 \times 10^{4}$ cells well ${ }^{-1}$. The cells were treated with $1 \mathrm{ml}$ fresh medium containing TAT-pK/pcDNA-EGFP complex ( $4 \mu \mathrm{g}$ of peptide and I $\mu \mathrm{g}$ of DNA) in the absence (left) or the presence of $100 \mu \mathrm{M}$ chloroquine (right). EGFP expression was detected with fluorescent microscopy as described under Materials and Methods. (B) Comparison of transfection activity of DOSPA/DOPE/DNA complex with TAT-pK/DNA complex and effects of ammonium chloride or chloroquine on TAT-pK-mediated gene transfer. HEK 293 cells $\left(5 \times 10^{4}\right.$ well $\left.^{-1}\right)$ were seeded into I2-well tissue culture plates. The cells were treated with DOSPAVDOPE/DNA complex $(2 \mu \mathrm{l}$ of DOSPA/DOPA and I $\mu$ g of DNA, open bar), according to the procedures recommended by the suppliers, or with TAT-pK/DNA complex ( $4 \mu \mathrm{g}$ of peptide and I $\mu \mathrm{g}$ of DNA) as described under Materials and Methods. The cells with TAT-pK/DNA complex were incubated for $48 \mathrm{~h}$ in the absence (filled bar) or presence (grey bars) of ammonium chloride $(25,50,100$, and $200 \mathrm{~mm}$ ) or chloroquine $(25,50,100$, and $200 \mu \mathrm{m})$. After incubation, cells were harvested and luciferase activity was evaluated. The luciferase activities were averaged from the results of duplicate experiments and are presented relative to the control value, indicated with the filled bar. (C) Cytotoxicity of ammonium chloride or chloroquine on HEK293 cells. Cells were seeded into 96-well plates and incubated at $37^{\circ} \mathrm{C}$ for $48 \mathrm{~h}$ in fresh medium containing a given concentration of ammonium chloride (left) or chloroquine (right) with (filled) or without (open) $20 \mu \mathrm{g} \mathrm{ml}^{-1}$ TAT-pK. After incubation, absorbance was measured by the WST-8 assay, as described under Materials and Methods. Each end point represents the mean \pm s.d.

Cell lines

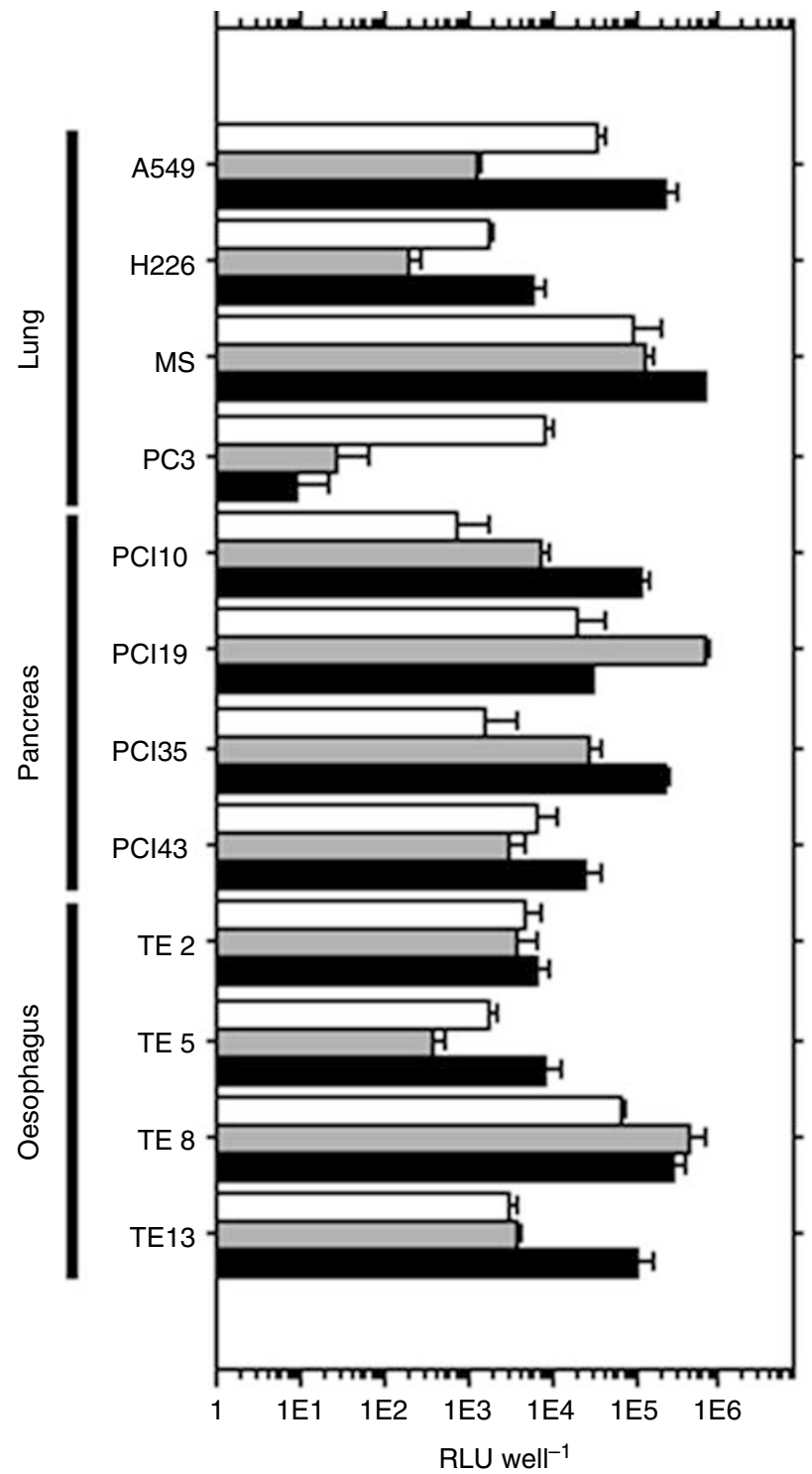

Figure 6 Transduction efficiency of DOSPA/DOPE or TAT-pK with chloroquine in various human cancer cell lines. Cells $\left(5 \times 10^{4}\right)$ were incubated with I $\mathrm{ml}$ medium containing $\mathrm{PGL3}$-promoter DNA $(\mathrm{I} \mu \mathrm{g})$ complexed with DOSPA/DOPA (open bars) or with TAT-pK in the presence of $50 \mu \mathrm{M}$ chloroquine (grey bars) or $100 \mu \mathrm{M}$ chloroquine (filled bars) and grown as described under Materials and Methods. After $48 \mathrm{~h}$ incubation, cells were harvested and luciferase activity was measured. Each end point represents the mean \pm s.d. RLU, relative light units.

modalities for efficiently transfecting pancreatic cancer cell lines. Initially, a recombinant Histidine6-tagged TAT-pK (H6-TAT-pK) construct was produced in E. coli strain BL21(DE3), carrying the pLysS plasmid (One Shot ${ }^{\mathrm{TM}}$; Invitrogen Corp., Carlsbad, CA, USA) to control leak-through expression and to allow subsequent cell lysis by freeze thawing. This construct was purified using a HiTrap $^{\mathrm{TM}}$ column (Amersham Pharmacia Biotech., Buckinghamshire, UK) and the ÄKTA prime ${ }^{\mathrm{TM}}$ system (Amersham Pharmacia Biotech), and a standard protocol for protein production was followed. The H6-TAT-pK/DNA complex was successfully introduced into PCI35 cells and EGFP expression was detected. The efficiency of transfection, however, was not better than with lipofection (data not shown). Subsequently, in order to elucidate the mechanism for TAT-pK-mediated gene transfer and to 
improve the efficiency, we synthesised TAT-pK without the His6 tag, as well as two control polypeptides GGG-pK and RGD-pK. The adenoviral RGD (Arg-Gly-Asp) motif AIRGDTFATGAS was fused to $\mathrm{pK}$ to compare the transfection efficiency with that of TAT-pK, because interaction of the RGD motif in the adenoviral penton base with cell membrane integrins is required to induce or trigger endocytosis (Wickham et al, 1993).

We anticipated that the cytotoxicity of TAT-pK would be stronger than that of RGD-pK, but interestingly, this was not the case. Actually, as cells would not be exposed to high concentrations for a prolonged time, toxicity is not likely to be a serious concern. No toxicity was observed, even at the highest doses examined for DNA transduction.

Most nonviral vehicles deliver their genes passively, relying on uptake into vesicular compartments by endocytosis, thus we examined the effects of ammonium chloride or chloroquine on transduction. Ammonium chloride is a weak acidotropic base. Chloroquine elevates the $\mathrm{pH}$ of vesicular compartments (Cotten et al, 1990), and either stimulates or inhibits the efficiency of endocytosis-mediated gene transfer, depending on the delivery vehicle. We found that TAT-pK-mediated gene transfer is affected by either of these agents, suggesting that transduction relies on the endocytic pathway. These results are similar to past reports showing that gene transfer via receptor-mediated endocytosis (Cotten et al, 1990) or mediated by DEAE-dextran (Luthman and Magnusson, 1983) is markedly enhanced with endosomotrophic agents, such as chloroquine. However, our data contradict other studies on TAT-peptide-mediated protein transduction (Mann and Frankel, 1991; Derossi et al, 1996; Vivès et al, 1997; Elliott and O'Hare, 1997) and TAT-phage-mediated gene transfer (Eguchi et al, 2001) that do not depend on endosomotrophic reagents. The mechanism of action of Tat- $(48-60)$ peptide and the full-length Tat protein may not be the same (Liu et al, 2000). Rather, TAT-pK-mediated gene transfer seems to share features of both systems, operating by both an energy-dependent endocytic pathway and an independent pathway. These dual mechanisms may account for the high efficiency of DNA transduction. In short, the Tat PTD anchors the TAT-pK/DNA complex to the cell surface within a few minutes by membrane destabilisation, and then the complex crosses the cell membrane by endocytosis.

The conditions suitable for gene transfer differed for each cell line. As PBS or RPMI medium reduce the efficiency of TAT-pKmediated gene transfer (data not shown), we used sterilised water for diluting pKs and only used DMEM in transfection. Transduction efficiency of TAT-pK was easily influenced by several factors, such as $\mathrm{pH}$ or temperature of medium, preincubation period, and quantity of DNA (data not shown). Moreover, the fold absorptions were decreased at high concentrations of chloroquine because of its cytotoxicity.

Several Tat PTD fused proteins have been reported as potential therapeutic strategies for cancer (Mann and Frankel, 1991; Derossi et al, 1996; Elliott and O'Hare, 1997; Vivès et al, 1997), but the quantity of protein transduced into tissues would be lower than that from administration of vector DNA. Moreover, selectivity and transduction efficiency are very important factors in order to apply gene therapy for cancer patients. Although we have not achieved targeting transduction for cancer cells by using TAT-pK, it may be easily modified to target cancerous, but not normal cells, since TAT-pK is much smaller than the capsid proteins of viral vectors. Also immunogenicity by TAT-pK should be investigated, but we do not think it higher than that of viral vectors because of its size. We have started in vivo experiments to assess these factors and to improve them.

In conclusion, although there is need for further improvement, TAT-pK is a candidate for a new DNA transfection system. Many problems still exist in clinical trials using viral vector-mediated gene therapy, therefore the development of artificial viral vector systems is urgently needed. TAT-pK is likely a minimal unit to efficiently package therapeutic genes and transduce them into mammalian cells.

\section{ACKNOWLEDGEMENTS}

This work was supported in part by a Grant-in Aid for Scientific Research from the Japan Society for the Promotion of Science, and from the Uehara Foundation.

\section{REFERENCES}

Colin M, Maurice M, Trugnan G, Kornprobst M, Harbotttle RP, Knight A, Cooper RG, Miller AD, Capeau J, Coutelle C, Brahimi-Horn MC (2000) Cell delivery, intracellular trafficking and expression of an integrinmediated gene transfer vector in tracheal epithelial cells. Gene Therapy 7: $139-152$

Cotten M, langle-Rouault F, Kirlappos H, Wagner E, Mechtler K, Zenke M, Beug H, Birnstiel ML (1990) Transferrin-polycation-mediated introduction of DNA into human leukemic cells: stimulation by agents that affect the survival of transfected DNA or modulate transferrin receptor levels. Proc Natl Acad Sci USA 87: 4033-4037

Derossi D, Calvet S, Trembleau A, Brunissen A, Chassaing G, Prochiantz A (1996) Cell internalization of the third helix of the Antennapedia homeodomain is receptor-independent. J Biol Chem 271: 18188-18193

Derossi D, Joliot AH, Chassaing G, Prochiantz A (1994) The third helix of the Antennapedia homeodomain translocates through biological membranes. J Biol Chem 269: $10444-10450$

Dostman WRG, Tayor MS, Nickl CK, Brayden JE, Frank R, Tegge WJ (2000) Antisense inhibition of P-glycoprotein expression using peptideoligonucleotide conjugates. Proc Natl Acad Sci USA 97: 14772-14777

Eguchi A, Akuta T, Okuyama H, Senda T, Yokoi H, Inokuchi H, Fujita S, Hayakawa T, Takeda K, Hasegawa M, Nakanishi M (2001) Protein transduction domain of HIV-1 Tat protein promotes efficient delivery of DNA into mammalian cells. J Biol Chem 276: 26204-26210

Elliott G, O'Hare P (1997) Intercellular trafficking and protein delivery by a herpesvirus structural protein. Cell 88: 223-233
Felgner PL, Barenholz Y, Behr JP, Cheng SH, Cullis P, Huang L, Jessee JA, Seymour L, Szoka F, Thierry AR, Wagner E, Wu G (1997) Nomenclature for synthetic gene delivery systems. Hum Gene Ther 8: 511-512

Fisher KJ, Choi H, Burda J, Chen S-J, Wilson JM (1996) Recombinant adenovirus deleted of all viral genes for gene therapy of cystic fibrosis. Virology 217: $11-22$

Futaki S, Suzuki T, Ohashi W, Yagami T, Tanaka S, Ueda K, Sugiura Y (2001) Arginine-rich peptides. An abundant source of membranepermeable peptides having potential as carriers for intracellular protein delivery. J Biol Chem 276: 5836-5840

Haecker SE, Stedmen HH, Balice-Gordon RJ, Smith DB, Greelish JP, Mitchell MA, Wells A, Sweeney HL, Wilson JM (1996) In vivo expression of full-length human dystrophin from adenoviral vectors deleted of all viral genes. Hum Gene Ther 7: 1907-1914

Kochanek S, Clemens PR, Mitani K, Chen H-H, Chan S, Caskey CT (1996) A new adenoviral vector: replacement of all viral coding sequences with $28 \mathrm{~kb}$ of DNA independently expressing both full-length dystrophin and beta-galactosidase. Proc Natl Acad Sci USA 93: 5731-5736

Kumar-Singh R, Chamberlain JS (1996) Encapsidated adenovirus minichromosomes allow delivery and expression of a $14 \mathrm{~kb}$ dystrophin cDNA to muscle cells. Hum Mol Genet 5: 913-921

Liu Y, Jones M, Hingtgen CM, Bu G, Laribee N, Tanzi RE, Moir RD, Nath A, He JJ (2000) Uptake of HIV-1 tat protein mediated by low-density lipoprotein receptor-related protein disrupts the neuronal metabolic balance of the receptor ligands. Nat Med 6: 1380-1387 
Fusion of HIV-I Tat protein

$\mathrm{H}$ Hashida et a

Luthman H, Magnusson G (1983) High efficiency polyoma DNA transfection of chloroquine treated cells. Nucleic Acids Res 11: 1295-1308

Mann DA, Frankel AD (1991) Endocytosis and targeting of exogenous HIV1 Tat protein. EMBO J 10: $1733-1739$

Morral N, O’Neal W, Rice K, Leland M, Kaplan J, Piedra PA, Zhou H, Parks RJ, Velji R, Aguilar-Cordova E, Wadsworth S, Graham FL, Kochanek S, Carey KD, Beaudet AL (1999) Administration of helper-dependent adenoviral vectors and sequential delivery of different vector serotype for long-term liver-directed gene transfer in baboons. Proc Natl Acad Sci USA 96: $12816-12821$

Nagahara H, Vocero-Akbani AM, Snyder EL, Ho A, Latham DG, Lissy NA, Becker-Hapak M, Ezhevsky SA, Dowdy SF (1998) Transduction of fulllength TAT fusion proteins into mammalian cells: TAT-p27Kip1 induces cell migration. Nat Med 4: 1449-1452

Perales JC, Ferkol T, Molas M, Hanson RW (1994) An evaluation of receptor-mediated gene transfer using synthetic DNA-ligand complexes. Eur J Biochem 226: 255-266
Schwartz SR, Ho A, Vocero-Akbani A, Dowdy SF (1999) In vivo protein transduction: delivery of a biologically active protein into the mouse. Science 285: 1569-1572

Suzuki T, Futaki S, Niwa M, Tanaka S, Ueda K, Sugiura Y (2002) Possible existence of common internalization mechanisms among arginine-rich peptides. J Biol Chem 277: 2437-2443

Vivès E, Brodin P, Lebleu B (1997) A truncated HIV-1 Tat protein basic domain rapidly translocates through the plasma membrane and accumulates in the cell nucleus. $J$ Biol Chem 272: $16010-16017$

Wagner E, Cotton M, Foisner R, Birnstiel ML (1991) Transferrinpolycation-DNA complexes: the effect of polycations on the structure of the complex and DNA delivery to cells. Proc Natl Acad Sci USA 88: $4255-4259$

Wickham TJ, Mathias P, Cheresh DA, Nemerow GR (1993) Integrins alpha $\mathrm{v}$ beta 3 and alpha $\mathrm{v}$ beta 5 promote adenovirus internalization but not virus attachment. Cell 73: 309-319 